\title{
Impact of noninvasive positive pressure ventilation on the gene expression of ubiquitin system of skeletal muscle in patients with acute exacerbation of chronic obstructive pulmonary disease
}

\author{
Hui Wang, Jingping Yang, Xiyuan Xu, Tieying Tian \\ Department of Respiratory and Critical Medicine, The Third Affiliated Hospital of Inner Mongolia Medical University, Baotou, \\ Inner Mongolia, China
}

Received: September 21, 2016

Accepted: October 21,2016

Online Published: December 10, 2016

DOI: $10.14725 /$ dcc.v3n4p1

URL: http://dx.doi.org/10.14725/dcc.v3n4p1

\begin{abstract}
Objective: To investigate the change and relativity of noninvasive positive pressure ventilation (NIPPV) on the gene expression of ubiquitin system of skeletal muscle in patient with acute exacerbation of chronic obstructive pulmonary disease (AECOPD). Methods: 80 patients with AECOPD were divided into two groups based on whether the NIPPV treatment was given or not, 38 cases in the study group and 42 in the control group. The blood gas analysis and pulmonary function were monitored and recorded before and 14 days after treatment. A skeletal muscle biopsy was performed 14 days after therapy. The mRNA expression of ribosomal protein S21 (RPS21) and ubiquitin in skeletal muscle cell were measured by RT-PCR.

Results: After 14 days treatment, the levels of $\mathrm{PaCO}_{2}, \mathrm{PaO}_{2}, \mathrm{PH}$ and $\mathrm{FEV}_{1} \%$ in the NIPPV group improved much better than in the control group $(p<.05)$. The gene expression of RPS21 and ubiquitin was obviously lower in the study group than in the control group $(p<.05)$. The level of RPS21 was negatively related with $\mathrm{PaO}_{2}, \mathrm{PH}$ and $\mathrm{FEV}_{1} \%$, and the level of ubiquitin was negatively related with $\mathrm{PaO}_{2}$ and $\mathrm{FEV}_{1} \%$, but positively correlated with $\mathrm{PaCO}_{2}$. The area under the ROC curves of RPS21, ubiquitin, $\mathrm{PaCO}_{2}$ and $\mathrm{FEV}_{1} \%$ were $0.771,0.885,0.821$ and 0.734 respectively in the study group. The cut-off points were $103.978,8.128,45.350$ and 51.350 respectively. The sensitivity evaluation of acid poisoning was $90.9 \%$, and the specificities for each were $75 \%, 75 \%, 50 \%$ and $50 \%$.

Conclusions: NIPPV is effective for AECOPD patients through the gene expression of ubiquitin system of skeletal muscle.
\end{abstract}

Key Words: Noninvasive positive pressure ventilation, Acute exacerbation of chronic obstructive pulmonary disease, Skeletal muscle, Gene expression

Chronic obstructive pulmonary disease is a common disease in respiratory system. Most of patients with this type of disease also suffer from malnutrition with the symptom of skeletal-muscle wasting and atrophy. The symptom is one of currently recognized extra-pulmonary manifestations and associated with the mortality. ${ }^{[1,2]}$ Currently, many researches have confirmed that the degradation of skeletal muscle protein is closely related to ubiquitin-proteasome pathway. ${ }^{[3]}$ However, if patients with acute exacerbation of chronic obstructive pulmonary disease (AECOPD) are given treatment with noninvasive positive pressure ventilation (NIPPV) at the appropriate time, it will effectively relieve respiratory muscle fatigue. ${ }^{[4]}$ It remains to be further studied whether NIPPV can impede the degradation of

\footnotetext{
*Correspondence: Jingping Yang; E-mail: yangron@sina.com; Address: Department of Respiratory and Critical Medicine, The Third Affiliated Hospital of Inner Mongolia Medical University, Baotou, Inner Mongolia 014010, China.
} 
skeletal muscle protein at the gene level. AECOPD patients given treatment with NIPPV were chosen as subjects in this research. The therapeutic effects of NIPPV on AECOPD patients were further illustrated by studying the blood gas analysis, pulmonary function and the change in skeletal muscle gene expression of AECOPD patients given treatment with NIPPV, as well as relativity among the three factors. The application of ROC curve can further verify that the gene expression of skeletal muscle can be used as a diagnostic assessment of AECOPD acid poisoning.

\section{Data and methods}

\subsection{Case selection and grouping}

70 cases of patients, who were diagnosed as AECOPD by systematic inspections in our department during August of 2012 to October of 2013, were chosen according to the diagnostic criteria in Chronic Obstructive Pulmonary Disease Diagnosis and Treatment Guideline (2013 Revised Edition) established by COPD Group of Chinese Thoracic Society, with indications to NIPPV. ${ }^{[5]}$ Patients who had contraindications or relative contraindications to NIPPV were excluded from this study. ${ }^{[4]}$ According to the fact that whether patients were willing to receive the treatment with NIPPV or not, the patients were divided into: NIPPV group of 38 cases, given the treatment with NIPPV (S/T mode; parameter: IPAP $14 \mathrm{cmH}_{2} \mathrm{O}$, EPAP $4 \mathrm{cmH}_{2} \mathrm{O}$ ), mainly night-time treatment, and the treatment time was more than 14 hours every day; Control group of 42 cases, not given the treatment with NIPPV. Before trial, it was required to acquire consents from the patients and their families with informed consent forms signed.

\subsection{Clinical observation indicators}

The blood gas analysis and the pulmonary function were recorded before treatment and 14 days after treatment.

\subsection{Muscle biopsy}

Vastus lateralis tissues on the left leg were collected by use of biopsy needles (specification: $14 \mathrm{Ga}, \mathrm{BARD}$ ) from patients with resting state both in the NIPPV group and the control group on the $14^{\text {th }}$-day treatment. Before collection, local anesthesia by use of $2 \%$ lidocaine was given to each patient, from which $100 \mathrm{mg}$ muscle tissues were collected and frozen by liquid nitrogen. The samples collected were then placed in the refrigerator with the temperature of $-80^{\circ} \mathrm{C}$.

\subsection{Measurement of mRNA expression of riboso- mal protein S21 (RPS21) and ubiquitin in skele- tal muscle by RT-PCR}

Trizol (Gibco, America) reagents were used to extract the skeletal muscle tissues placed at $-80^{\circ} \mathrm{C}$ in the refrigerator. The UV spectrophotometer (Eppendoff, Germany) was applied to the measurement of RNA purity and content. RTPCR kits (Takara, Dalian) were used in reverse transcription. Gene primers of RPS21 and ubiquitin Ubc were synthesized in Beijing Liuhe BGI Science \& Technology Co., Ltd. $5 \mu \mathrm{L}$ of PCR products were added by $1 \mu \mathrm{L}$ of loading buffer and mixed together, and then added to the loading well with DNA markers as indicators. After 40-minute electrophoresis, the results were observed and photographed on the FR-200 UV analyzer. The electrophoretic bands were scanned and analyzed by Smart View 2000 bioelectrophoresis image analysis software to calculate integrated optical density (area $\times$ optical density). Relative content of gene expression was represented by the ratio of integrated optical density of target gene to that of internal reference GAPDH.

\subsection{Statistical treatment}

The experimental data were analyzed by SPSS 13.0 statistical software and represented by $\bar{x} \pm \mathrm{s}$. The comparison between specimen means was made by use of $t$-test; the correlation of two variables was determined by linear correlation analysis (Pearson method) to calculate correlation coefficient $(r)$, the difference $p<.05$ was of statistical significance. The diagnostic efficacy was analyzed by ROC curve, and the difference $p<.05$ was statistically significant.

\section{Results}

\subsection{Effects of NIPPV on the blood gas analysis and the pulmonary function of patients with AE- COPD}

In 14 days after treatment, the levels of $\mathrm{PaCO}_{2}, \mathrm{PaO}_{2}, \mathrm{pH}$ and $\mathrm{FEV}_{1} \%$ were obviously improved, and the difference ( $p$ $<.05$ ) was statistically significant (see Table 1).

\subsection{Measurement of mRNA expression of RPS21 and ubiquitin in skeletal muscle by RT-PCR}

The mRNA expression of RPS21 and ubiquitin in NIPPV group were: $98.2 \pm 45.9$ and $9.5 \pm 0.9$ respectively; the mRNA expression of RPS21 and ubiquitin in skeletal muscle in the control group were: $214.5 \pm 28.9$ and $13.5 \pm 2.8$ respectively. The mRNA expression of RPS 21 and ubiquitin in skeletal muscle in NIPPV group was obviously lower than that in the control group, $p<.0001, p<.05$ (see Figure $1)$. 
Table 1: Effects of NIPPV on the blood analysis and the pulmonary function of AECOPD patients $(\bar{x} \pm \mathrm{s})$

\begin{tabular}{llllll}
\hline & \multicolumn{2}{c}{ NIPPV Group } & & \multicolumn{2}{c}{ Control Group } \\
\cline { 2 - 3 } \cline { 5 - 6 } & Before Treatment & After Treatment & & Before Treatment & After Treatment \\
\hline $\mathrm{PaCO}_{2}(\mathrm{mmHg})$ & $67.1 \pm 7.6$ & $52.9 \pm 8.1^{*}$ & & $65.2 \pm 12$ & $60.2 \pm 11$ \\
$\mathrm{PaO}_{2}(\mathrm{mmHg})$ & $56.8 \pm 8.9$ & $77.8 \pm 10.4^{*}$ & & $55.2 \pm 15$ & $69.2 \pm 13$ \\
$\mathrm{pH}$ & $7.18 \pm 0.15$ & $7.36 \pm 0.14^{*}$ & & $7.17 \pm 0.05$ & $7.35 \pm 0.08$ \\
$\mathrm{FEV}$ & $39.6 \pm 5.2$ & $49.1 \pm 6.1^{*}$ & & $38.2 \pm 6.5$ & $47.1 \pm 2.3$ \\
\hline
\end{tabular}

Note. In comparison with the control group after treatment, ${ }^{*} p<.05$
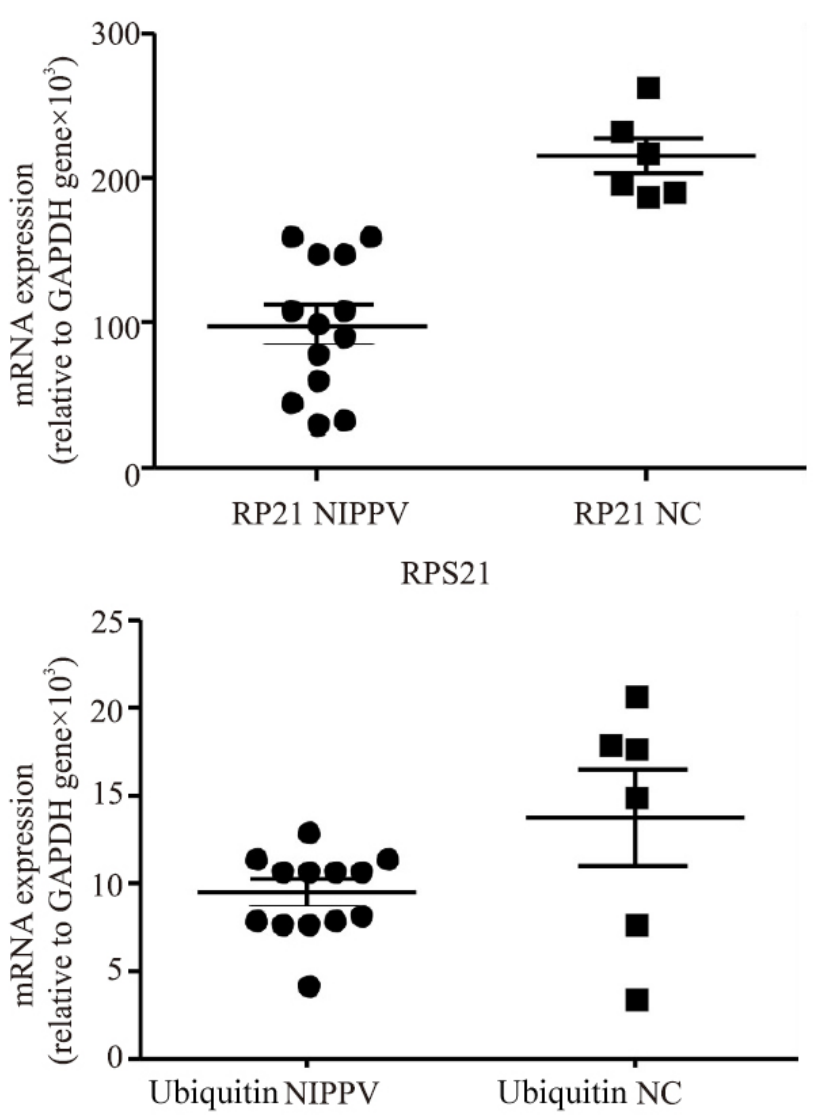

Figure 1: Comparison of gene expression of RPS21 and ubiquitin in skeletal muscle between NIPPV group and the control group

\subsection{Analysis of correlation between gene expression and the levels of $\mathrm{PaCO}_{2}, \mathrm{PaO}_{2}, \mathrm{pH}$ and $\mathrm{FEV}_{1} \%$ in skeletal muscle in NIPPV group after 14-day treatment}

The expression of RPS21 was negatively correlated with the levels of $\mathrm{PaO}_{2}, \mathrm{pH}$ and $\mathrm{FEV}_{1} \%, p<.05$, and $r$-values were $-0.8150,-0.7339$ and -0.8575 respectively; the expression of RPS21 had no correlation with the level of $\mathrm{PaCO}_{2}, p=$ .2857 .

The expression of ubiquitin was obviously negatively correlated with the levels of $\mathrm{PaO}_{2}$ and $\mathrm{FEV}_{1} \%, p<.05, r$-values were -0.8565 and -0.8634 respectively; the expression of ubiquitin was positively correlated with the level of $\mathrm{PaCO}_{2}$, $p<.05, r=0.6422$; and the expression of ubiquitin had no correlation with the level of $\mathrm{pH}, p=.095$.

\subsection{AECOPD acid poisoning diagnosed ROC curves of RPS21, ubiquitin, $\mathrm{FEV}_{1} \%$ and $\mathrm{PaCO}_{2}$}

The area under the ROC curve of RPS21 was $0.773, p=$ .48; the area under the ROC curve of ubiquitin was 0.875 , $p=.005$; the area under the ROC curve of $\mathrm{PaCO}_{2}$ was 0.813 , $p=.023$; and the area under the ROC curve of $\mathrm{FEV}_{1} \%$ was $0.756, p=.63$ (see Table 2 and Figure 2).

\section{Discussions}

In recent years, NIPPV has been increasingly applied to the clinical treatment of AECOPD with respiratory failure for its easy-to-operate, non-invasion, effectiveness and other characteristics. ${ }^{[6]}$ However, in the process of clinical application, the therapeutic effects of NIPPV were directly affected by various factors and poor treatment compliance (part of patients). Consequently, NIPPV was doubted by part of scholars. Therefore, this study not only explained the therapeutic effects of NIPPV on AECOPD patients from the aspect of the improvement in the blood analysis and the pulmonary function, but also illustrated those effects at the gene level of skeletal muscle. The experimental objective signs and the change in the gene expression of skeletal muscle were indicated and then given correlation analyses.

The researches at home and abroad have showed that, ${ }^{[7-10]}$ the increase in degradation rate of skeletal muscle protein in AECOPD patients can lead to skeletal-muscle atrophy. However, the process of protein degradation can be divided into 2 steps: at first, with the participation of ATP, ubiquitinactivating enzyme (E1) activates ubiquitin by acting on glutamic acid residue at the end of ubiquitin hydroxy; and then, the activated ubiquitin is bound to L-Cysteine residue of ubiquitin-conjugating enzyme (E2) by use of high-energy sulphydryl bond. ${ }^{[1]]}$ Secondly, E2 connects ubiquitin to target protein directly or by use of ubiquitin ligase (E3) to complete the ubiquitination of proteins. ${ }^{[12]}$ The gene of RPS21 
belongs to the ribosome family. Researches have shown that RPS21 participates in the regulation of protein synthesis and cell growth. Aerobic exercise can lower the expression of RPS21, and then suppress the growth of inflammatory cells in patients with chronic obstructive pulmonary disease. Meanwhile, it can also lower the gene expression of programmed cell death, and has a positive effect on improving the activity and the lifetime of normal cells.

Table 2: The areas under the ROC curves of RPS21, ubiquitin, $\mathrm{FEV}_{1}$ and $\mathrm{PaCO}_{2}$ in skeletal muscle in NIPPV group

\begin{tabular}{llllll}
\hline & Area & $\boldsymbol{p}$-value & Cut-off Point & Sensitivity (\%) & Specificity (\%) \\
\hline RPS21 & 0.771 & .048 & 103.978 & 90.9 & 75 \\
Ubiquitin & 0.885 & .006 & 8.128 & 90.9 & 75 \\
$\mathrm{PaCO}_{2}$ & 0.821 & .023 & 45.350 & 90.9 & 50 \\
$\mathrm{FEV}_{1} \%$ & 0.734 & .063 & 51.350 & 90.9 & 50 \\
\hline
\end{tabular}

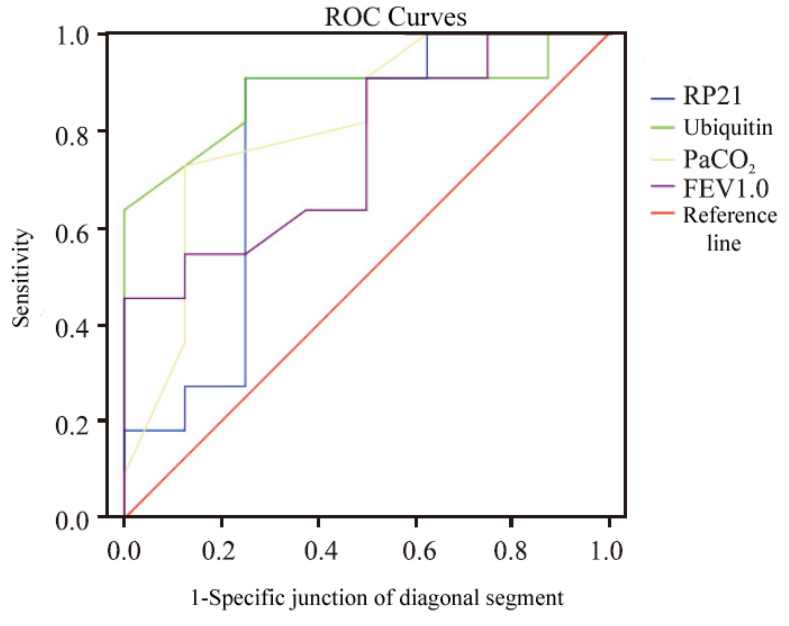

Figure 2: The areas under the ROC curves of RPS21, ubiquitin, $\mathrm{FEV}_{1}$ and $\mathrm{PaCO}_{2}$ in skeletal muscle in NIPPV group

This research showed that the blood gas analysis and the pulmonary function in NIPPV group of AECOPD patients were obviously improved after treatment in comparison with the control group, the mRNA expression of RPS2 1 and ubiquitin in skeletal muscle in NIPPV group was obviously lower than that in the control group $(p<.05)$. It is indicated that the application of NIPPV can inhibit the degradation of protein in skeletal muscle, partially recover the function of skeletal muscle, suppress the growth of inflammatory cells in AECOPD patients and the gene expression of programmed cell death, and improve the activity of skeletal muscle cells.

The results in this study have shown that the mRNA expression of ubiquitin and RPS21 in skeletal muscle in patients of NIPPV group was lower than that in the control group, and it is negatively correlated with $\mathrm{PaO}_{2}$ and $\mathrm{FEV}_{1}$. It is further indicated that the application of NIPPV treatment can not only improve the function of skeletal muscle through the change in the gene expression, but also make the patient's ventilation condition better in order to realize the therapeutic effects. However, the mRNA expression of ubiquitin has no correlation with $\mathrm{pH}$, and the mRNA expression of RPS21 has no correlation with $\mathrm{PaCO}_{2}$ either. Considering the lim4 ited number of cases involved in this research and internal related influencing factors, it remains to be further studied.

In the analysis of the ROC curve, it is acknowledged that it is important to select a gold standard. If the gold standard is improperly selected, it will lead to the deviation of results. Currently, in many medical literatures and clinical application, $\mathrm{pH}$ value in the blood gas analysis is the most sensitive indicator reflecting whether AECOPD patients suffer from acid poisoning. Meanwhile, this research confirms that $\mathrm{pH}$ value has a good correlation with the gene expression of RPS21 in skeletal muscle. With the aid of ROC curves, this research further confirms that the change in mRNA expression of $\mathrm{PaCO}_{2}$, ubiquitin and RPS21 is of high sensitivity to the diagnosis of acid poisoning, $p<.05$. Ubiquitin has a good correlation with $\mathrm{PaCO}_{2}$, and then it is in favor of clinical physicians to make better use of simple and objective indicators derived from experimental results to investigate the internal change of skeletal muscle in AECOPD patients after treatment with NIPPV. However, the analysis of ROC curves in this research has shown that the change in $\mathrm{FEV}_{1}$ can not be used to determine whether AECOPD patients suffer from acid poisoning. Although the ROC curve is associated with the patient's pulmonary function grading and compensatory mechanism, the correlation with the limited number of cases in this study cannot be excluded. Therefore, it remains to be further studied.

To be concluded, this research can not only confirm the improved AECOPD patients' ventilation conditions after NIPPV treatment according to the blood gas analysis and pulmonary function at the experimental level, but also confirm that NIPPV can impede the degradation of skeletal muscle protein at the gene level and improve patient's ventilation condition, to avoid or relieve the pains caused by tracheal intubation or incision, as well as reduce the incidence of pulmonary infection and its mortality. However, it remains to be further studied that how long NIPPV treatment takes to reverse skeletal-muscle malnutrition.

\section{Conflicts of Interest Disclosure}

The authors have no conflicts of interest related to this article.

ISSN 2375-8449 E-ISSN 2375-8473 


\section{References}

[1] COPD Group of Chinese Thoracic Society. Chronic Obstructive Pulmonary Disease Diagnosis and Treatment Guideline (2007 Revised Edition). Chinese Journal of Tuberculosis and Respiratory Diseases. 2007; 30(1): 8-17.

[2] Mador MJ. Muscle mass, not body weight, Prediets outcome in Patients wiht chronic obstructive Pulmonary disease. Am J Respir Cirt Med. 2002; 166: 787-789. PMid: 12231484. https://doi.org/ 10.1164/rccm. 2206003

[3] Altun M, Besche HC, Overkleeft HS, et al. Muscle wasting inaged, sarcopenic rats is associated with enhanced activity of the ubiquitin proteasome pathway. J Biol Chem. 2010; 285: 39597-39608. PMid: 20940294. https://doi.org/10.1074/jbc.M110.129718

[4] Bao SZ, Wang XT. Skeletal Muscle Dysfunction in Patients with Chronic Obstructive Pulminary Disease. Chinese Journal of Clinical Neurosciences. 2009; 17(1): 106-109.

[5] COPD Group of Chinese Thoracic Society. Chronic Obstructive Pulmonary Disease Diagnosis and Treatment Guideline (2013 Revised Edition). Chinese Journal of Tuberculosis and Respiratory Diseases. 2013; 36(4): 255-264.

[6] Wang CY, Qin J. The Effect Analysis of Non-invasive Positive Pressure Ventilation in Elderly Patients with Acute Exacerbation of COPD. China Medicine. 2010; 5(7): 600-601.
[7] Ptak C, Gwozd C, Huzil JT, et al. Creation of a Pluripotent Ubiquitin-Conjugating Enzyme. Mol Cell Biol. 2001; 21(19): 6537 6548. PMid: 11533242. https://doi.org/10.1128/MCB. 21. $19.6537-6548.2001$

[8] Han FF, Luo Y, Xu WG, Changes in Expression of mRNA and Protein of 20s Proteasome Subunit C2 in Skeletal Muscle in COPD Rats. Chinese General Practice. 2010; 13(10B): 3289-3292.

[9] Yang Y, Dai LM, Research Progress of Mechanisms of Skeletal Muscle Atrophy in Chronic Obstructive Pulmonary Disease. Medical Information. 2010; 23(11): 4117-4118.

[10] Debigaré R, Marquis K, Côté CH, et al. Catabolic/anabolic balance and muscle wasting in patients with COPD. Chest. $2003 \mathrm{Jul}$; 124(1): 83-89. PMid: 12853506. https://doi.org/10.1378/ chest.124.1.83

[11] Kim MS, Sweeney TR, Shigenaga JK, et al. Tumor necrosis factorand interleukin 1 decrease RXRalpha, PPARalpha, PPARgamma, LXRalpha, and the coactivators SRC-1, PGC-1alpha, and PGC1beta in liver cells. Metabolism. 2007; 56(2): 267-279. PMid: 17224343. https://doi.org/10.1016/j.metabol.2006.10. 007

[12] Liang JK, Wu MQ, Sheng ZY. Effect of Sepsis on the Expression of Ubiquitinated Protein in Rat Skeletal Muscle. Chinese Journal of Surgery. 2001; 39(9): 721-723. 